\title{
Dinámica de la transferencia de inmunoglobulina G en el binomio madre-cría de la especie caprina
}

\author{
Cooper, L.G.; Auad, J.; Cerutti, J.; Lozano, A.; Aguilar Sola, M.S. \\ Universidad Católica de Córdoba. Unidad Asociada a CONICET - Área de CS. AGR. ING. BIO. y S. \\ Av. Armada Argentina 3555, Córdoba, CP X5016DHK, Tel. 0351-4938000, \\ E-mail: lauracooper13@hotmail.com
}

\begin{abstract}
Resumen
Cooper, L.G.; Auad, J.; Cerutti, J.; Lozano, A.; Aguilar Sola, M.S.: Dinámica de la transferencia de inmunoglobulina $G$ en el binomio madre-cría de la especie caprina. Rev. vet. 25: 2, 105-108, 2014. La placenta de la cabra impide el pasaje de anticuerpos desde la circulación materna a la fetal. Por tanto, éstos son transferidos luego del nacimiento a través del calostro ingerido. Los objetivos del ensayo fueron establecer la cinética de la concentración de inmunoglobulina $\mathrm{G}(\operatorname{IgG})$ en cabritos durante sus primeros 5 meses de vida y relacionar la concentración de $\mathrm{IgG}$ en suero y calostro de cabra con la concentración en suero del cabrito, así como evidenciar si existen diferencias en la cinética de la concentración de IgG de cabritos respecto al tamaño de la camada. Se utilizaron 16 cabras Anglo Nubian y 26 crías divididas en dos grupos según el tamaño de la camada. Las concentraciones de $\operatorname{IgG}$ en calostro y suero se valoraron por inmunodifusión radial. Los resultados mostraron que las concentraciones de $\operatorname{IgG}$ en suero y calostro de cabras fueron de 1749 y $3720 \mathrm{mg} / \mathrm{dl}(\mathrm{p}<0,001)$. En los cabritos los valores fueron no medibles a las $0 \mathrm{~h}$ y máximos a las $18 \mathrm{~h}(1814 \mathrm{mg} / \mathrm{dl})$. A los 21 días, la concentración sérica de $\mathrm{IgG}$ en cabritos fue de $1677 \mathrm{mg} / \mathrm{dl}$, valor significativamente diferente al de las cabras y al de los cabritos a las $18 \mathrm{~h}(\mathrm{p}<0,001)$. Con respecto al tamaño de la camada no se encontraron diferencias en las concentraciones de $\operatorname{IgG}$ en suero y calostro de cabras $(p=0,77)$, al igual que en la cinética en suero de los cabritos $(p=0,48)$. Se concluye que los niveles de IgG en cabritos se mantienen en valores similares a los de sus madres desde las $6 \mathrm{~h}$ hasta los 150 días y que el tamaño de la camada no influye en la concentración de $\operatorname{IgG}$ de los cabritos.
\end{abstract}

Palabras clave: cabra, calostro, IgG, inmunodifusión radial, tamaño de camada.

\begin{abstract}
Cooper, L.G.; Auad, J.; Cerutti, J.; Lozano, A.; Aguilar Sola, M.S.: Transfer dynamics of immunoglobulin $\mathbf{G}$ in mother and kid goats. Rev. vet. 25: 2, 105-108, 2014. The goat placenta prevents the passage of maternal antibodies to fetal circulation so these are transferred via colostrum which must be ingested after birth. The objective of the trial was to establish the kinetics of the concentration of immunoglobulin $\mathrm{G}(\operatorname{IgG})$ in goat kids in the first 5 months of life; to relate the concentration of $\operatorname{IgG}$ in serum and colostrum of goat with concentration in serum of kid; to evidence differences in the kinetics of IgG concentration of kids regarding litter size. Sixteen Anglo Nubian goats and 26 kids were divided in two groups according to litter size. IgG was measure by single radial immunodiffusion. The concentration of IgG was $1749 \mathrm{mg} / \mathrm{dl}$ in serum and $3720 \mathrm{mg} / \mathrm{dl}$ in colostrum $(\mathrm{p}<0.001)$. In kids at $0 \mathrm{~h}$ the values were not detectable, reaching peak at $18 \mathrm{~h}(1814 \mathrm{mg} / \mathrm{dl})$ with a decrease between $24 \mathrm{~h}$ and 60 days $(\mathrm{p}<0.001)$. Regarding litter size, it did no influence the concentration of serum IgG and goat colostrum ( $p$ 0.77), as well as for the serum kinetics of kids ( $p$ 0.48). In conclusion, IgG levels in the kids are kept at a similar concentration of the mothers from $6 \mathrm{~h}$ to 150 days. Between $24 \mathrm{~h}$ and 60 days there is a reduction in serum IgG compared to the average kinetic obtained. The litter size does not influence the concentration of $\operatorname{IgG}$ in goat kids.
\end{abstract}

Key words: goat, colostrum, $\operatorname{IgG}$, radial immunodiffusion, litter size. 


\section{INTRODUCCIÓN}

La producción caprina adquiere una importancia fundamental en la economía de la Provincia de Córdoba (Argentina), ya que se extiende por todo el norte y oeste provincial. El bajo nivel de tecnificación lleva a que existan condiciones de infraestructura muy precarias para el desarrollo de la actividad, así como también desconocimiento o mala utilización de prácticas de manejo ${ }^{1}$.

Numerosos factores contribuyen a la mortalidad temprana de los cabritos, incluyendo bajo peso al nacer, nacimiento prematuro, camadas numerosas, mala actitud materna e hipotermia, así como condiciones ambientales y climáticas hostiles ${ }^{9}$. Sin embargo, el factor más importante para garantizar la supervivencia y correcto desarrollo de los cabritos es la ingestión de calostro, ya que la placenta de los caprinos, sindesmocorial, impide el pasaje de anticuerpos de la circulación materna a la fetal ${ }^{15}$. Por tanto, el cabrito nace sin protección específica contra los desafíos patogénicos del ambiente al que se enfrenta, necesitando de las inmunoglobulinas (Igs) sintetizadas y oriundas de la madre, transferidas a través de un único vehículo, el calostro ${ }^{6,7}$.

En los caprinos, así como en los demás rumiantes, el calostro es rico en IgG, IgA e IgM, siendo IgG la principal clase de inmunoglobulina ${ }^{9}$. Ésta es absorbida por el neonato en el intestino delgado por células especializadas que presentan una vida media efímera (24 a 36 horas) ${ }^{3}$. Las Igs se unen a receptores Fc en las células epiteliales del intestino $(\mathrm{FcRn}){ }^{13}$. Estas células especializadas las captan en forma activa por medio de pinocitosis. Luego, las inmunoglobulinas se dirigen a los quilíferos y capilares intestinales ${ }^{11}$, para alcanzar la circulación sistémica de los neonatos, obteniendo así una transfusión masiva de Igs maternas ${ }^{17}$.

La primera ingestión de calostro debe ocurrir inmediatamente luego del nacimiento y es recomendable que en cabritos sea del 5 al $7 \%$ del peso vivo dentro de las primeras 6 a 8 horas de vida, momento en el cual la absorción intestinal es máxima, pues luego disminuirá progresivamente hasta hacerse nula a partir de las $24 \mathrm{~h}$ postparto ${ }^{8}$. En tal contexto, los objetivos de este trabajo fueron:

- Establecer la cinética de la concentración de IgG en cabritos en los primeros 5 meses de vida.

- Relacionar la concentración de IgG en suero y calostro de la cabra con la concentración de IgG en el suero del cabrito.

- Evidenciar si existen diferencias en la cinética de la concentración de IgG de los cabritos respecto al tamaño de la camada.

\section{MATERIAL Y MÉTODOS}

Diseño del estudio, población: se empleó un diseño experimental de cohortes, observacional y analítico. Se estudiaron 16 cabras Anglo Nubian y sus respectivas 26 crías del Campus Experimental de la Facultad de Ciencias Agropecuarias de la Universidad Católica de Córdoba (Argentina). Se las dividió en dos grupos según el tamaño de la camada; monotocas: constituido por 6 cabras y 6 cabritos y politocas: cabras que parieron dos crías, grupo conformado por 10 hembras y 20 cabritos.

Muestras de material biológico: se tomaron $5 \mathrm{ml}$ de sangre por punción de la vena yugular a las cabras en el periparto y una muestra de $20 \mathrm{ml}$ de calostro postparto de ambos medios de la glándula mamaria previo a la succión del cabrito. Por otra parte, se extrajo sangre por punción de la vena yugular a los cabritos de acuerdo a la siguiente cinética: $0,6,12,18$ y 24 horas de nacido y $21,60,90,120$ y 150 días postparto. Las muestras de suero y calostro fueron almacenadas y congeladas a $-80^{\circ} \mathrm{C}$ hasta su procesamiento.

Determinaciones de laboratorio: $\operatorname{las} \mathrm{IgG}$ se cuantificaron por inmunodifusión radial simple, aplicándose una técnica convencional ${ }^{10}$ empleando Rabbit AntiGoat IgG ${ }^{\circledR}$ (Jackson ImmunoResearch Laboratories, West Grove, PA, USA). Se realizó curva de calibración con un estándar de concentración conocida (Goat Gamma Globulin $1000 \mathrm{mg} / \mathrm{dl} \circledast$ Jackson ImmunoResearch Laboratories, West Grove, PA, USA). Se tiñó la placa de inmunodifusión con azul brillante de Coomassie y la lectura de los halos se realizó mediante la toma de imágenes y la medición de los diámetros correspondientes a través del dispositivo periférico WebCam Philips SPC- $530 \mathrm{Nc} \circledast$, 1,3 Mp zoom óptico x3, empleando el software Philips CamSuite Capture ${ }^{\circledR}$ V.2.0.15.0. Las imágenes se procesaron mediante el software Carl Zeiss AxioVision ${ }^{\circledR}$ Rel. 4.6.

Análisis estadístico: se realizaron tests descriptivos y analíticos utilizando modelos lineales generalizados mixtos. Para la comparación entre grupos se empleó prueba t para muestras independientes o dependientes según correspondiera. Se consideró significativo un valor de $\mathrm{p}<0,05$.

\section{RESULTADOS}

En las cabras la concentración de IgG en suero fue de $1749 \mathrm{mg} / \mathrm{dl}$ y en calostro de $3720 \mathrm{mg} / \mathrm{dl}$. Los valores postparto obtenidos en los cabritos según la cinética establecida se detallan en la Tabla 1.

A las cero horas postparto los valores de la concentración de IgG en los cabritos fueron no medibles, para comenzar a aumentar a medida que se producía la absorción del calostro. A las 6 horas postparto los cabritos presentaron una concentración de IgG significativamente menor a la de sus madres $(\mathrm{p}<0,001)$, alcanzando valores máximos y superiores a éstas a las 18 horas postparto $(p<0,001)$, momento en el que el intestino deja de ser permeable a la absorción de IgG. A partir de allí, los niveles de IgG comenzaron a descender. Si bien la concentración se mantuvo en un rango fisioló- 
Tabla 1. Concentración de IgG en suero y calostro de cabras, así como suero de cabritos a diferentes intervalos (cinética).

\begin{tabular}{lcccc}
\hline muestra & $\overline{\mathrm{x}}(\mathrm{mg} / \mathrm{dl})$ & EE & Li & Ls \\
\hline suero cabra & 1749 & 19 & 1712 & 1786 \\
calostro & 3720 & 19 & 3683 & 3757 \\
SC $(0$ horas $)$ & ND & 0 & 0 & 0 \\
SC (6 horas) & 1700 & 21 & 1660 & 1742 \\
SC $(12$ horas $)$ & 1798 & 19 & 1761 & 1836 \\
SC $(18$ horas $)$ & 1814 & 19 & 1777 & 1852 \\
SC $(24$ horas $)$ & 1793 & 19 & 1755 & 1830 \\
SC $(21$ días $)$ & 1677 & 19 & 1639 & 1715 \\
SC $(60$ días $)$ & 1686 & 20 & 1647 & 1724 \\
SC $(90$ días $)$ & 1735 & 20 & 1695 & 1775 \\
SC $(120$ días $)$ & 1756 & 21 & 1714 & 1798 \\
SC $(150$ días $)$ & 1752 & 20 & 1712 & 1793 \\
\hline
\end{tabular}

$\overline{\mathrm{X}}$ : media aritmética, EE: error estándar, Li: límite inferior, Ls: límite superior, SC: suero de cabritos, ND: no dosable.

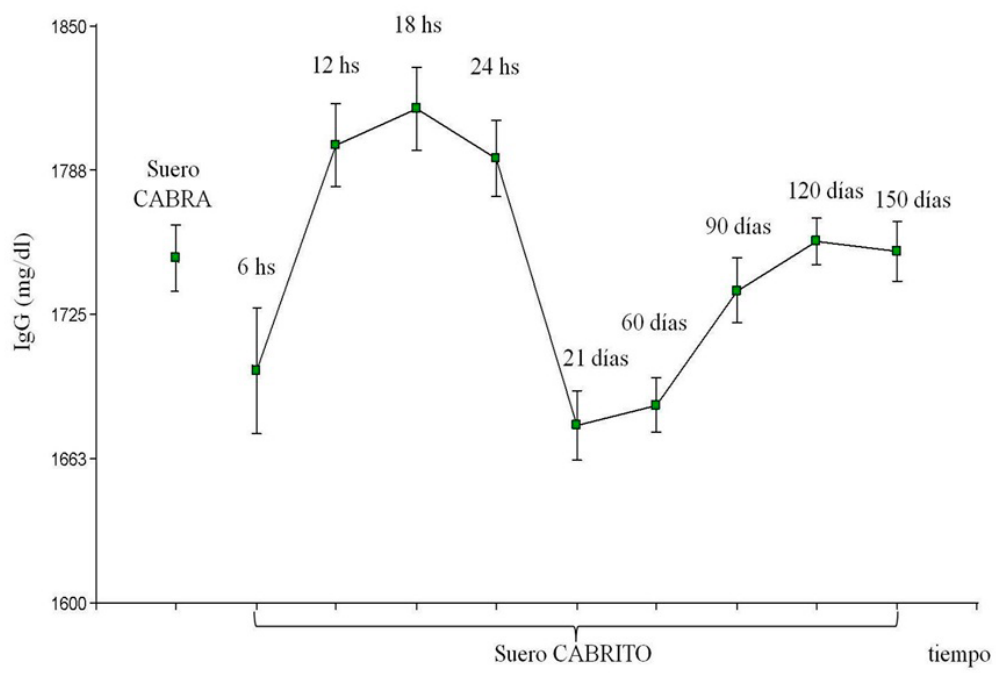

Figura 1. Concentración de IgG en suero de cabras y cinética en suero de cabritos hasta los 150 días postparto.

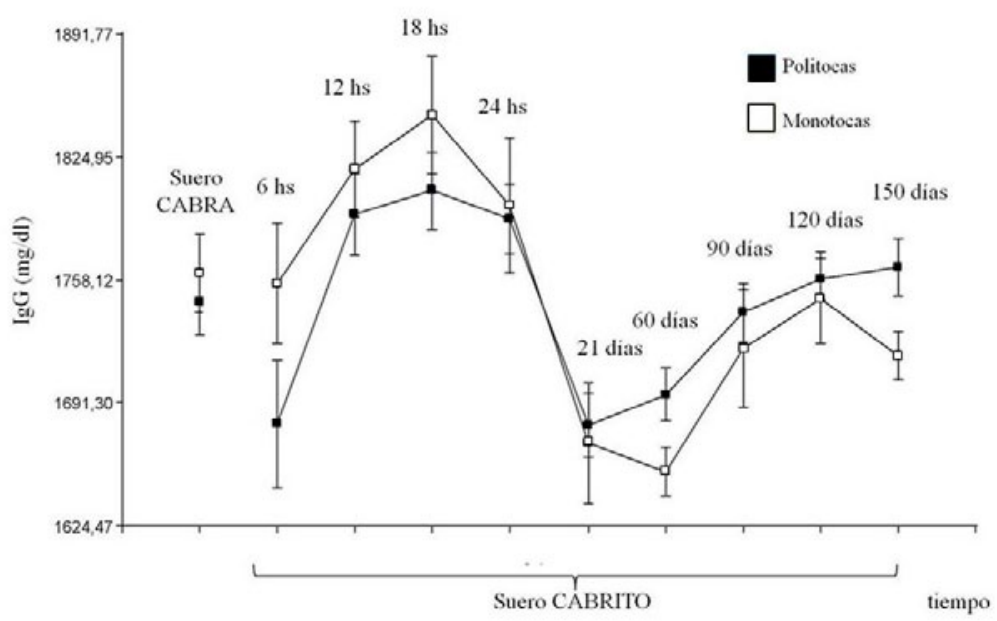

Figura 2. Concentración de IgG en suero de cabras y cinética en los cabritos a diferentes intervalos, según el tamaño de la camada.
Tabla 2. Concentración de $\mathrm{IgG}(\mathrm{mg} / \mathrm{dl})$ en suero y calostro de cabras de acuerdo al tamaño de la camada.

\begin{tabular}{lccc}
\hline variable & $\begin{array}{c}\text { monotocas } \\
\mathrm{n}=6\end{array}$ & $\begin{array}{c}\text { politocas } \\
\mathrm{n}=10\end{array}$ & $\mathrm{p}$ \\
\hline $\begin{array}{l}\text { IgG sérica } \\
\overline{\mathrm{x}} \pm \mathrm{EE}\end{array}$ & $1762 \pm 51$ & $1744 \pm 78$ & 0,68 \\
$\begin{array}{l}\text { IgG calostro } \\
\overline{\mathrm{x}} \pm \text { EE }\end{array}$ & $3693 \pm 226$ & $3726 \pm 185$ & 0,77 \\
$\mathrm{p}$ & 0,0001 & 0,0001 & \\
\hline
\end{tabular}

$\overline{\mathrm{X}}$ : media aritmética, EE: error estándar, p: significancia.

gico hasta los 150 días, la diferencia entre las 24 horas y los 60 días fue significativa ( $\mathrm{p}<0,001)$, evidenciando en este intervalo un descenso en los niveles de IgG del suero de los cabritos (Figura 1).

Se encontraron diferencias significativas $(p<0,001)$ entre las concentraciones de IgG en calostro $(3720 \mathrm{mg} /$ dl) versus suero de las cabras (1749 mg/dl) y también entre calostro versus suero de los cabritos a las 24 horas $(1793 \mathrm{mg} / \mathrm{dl})$.

Con respecto al tamaño de la camada no se encontraron diferencias significativas en la concentración de $\operatorname{IgG}$ en suero y calostro de la cabra $(\mathrm{p}=0,77)$ como se observa en la Tabla 2, al igual que en la cinética de esta inmunoglobulina en el suero de los cabritos $(\mathrm{p}=0,48)$ (Figura 2).

\section{DISCUSIÓN}

La concentración de IgG de los cabritos a las cero horas postparto no fue medible, hallazgo que concuerda con los resultados de otros investigadores ${ }^{12} \mathrm{y}$ que se fundamenta en el tipo de placenta presente en esta especie. Las concentraciones más altas de IgG en suero de cabritos se registraron a las $18 \mathrm{~h}$ postparto; en otros ensayos tal concentración máxima se halló a las $24 \mathrm{~h}$ postparto ${ }^{5} \mathrm{o}$ bien entre las 24 y $60 \mathrm{~h} \mathrm{de} \mathrm{vida}^{2}$.

Si bien existen diferencias con otros autores en los tiempos en que fueron hallados los valores máximos de $\operatorname{IgG}$ en suero de cabritos, los parámetros son comparables. Aunque la concentración de estos anticuerpos se mantuvo en un rango fisiológico hasta los 150 días, la diferencia entre las 24 h y los 60 días fue significativa, lo que puede ser explicado por el catabolismo de las inmunoglobulinas maternas. Hallazgos similares fueron encontrados por investigadores que reportan las menores concentraciones de IgG a las 4 semanas postparto ${ }^{14} \mathrm{y}$ otros que las señalan a los 30 días de vida ${ }^{3}$. 
Con respecto al tamaño de la camada no se encontraron diferencias significativas en la concentración de IgG en suero y calostro de la cabra, al igual que en la cinética de esta inmunoglobulina en el suero de los cabritos. Nuestros resultados coinciden con los obtenidos por algunos investigadores ${ }^{4}$ pero difieren con los reportados por otros ${ }^{5}$, quienes encontraron diferencias significativas en cabritos hijos de madres monotocas en contraste con cabritos hijos de madres politocas. Tal diferencia podría ser atribuible al tamaño muestral analizado en los diferentes grupos de estudio ${ }^{4,5}$. Los cabritos hijos de cabras monotocas son escasos, dada la característica biológica de la especie, donde la mayoría de las madres presenta gestaciones múltiples ${ }^{16}$.

Se concluye que en los cabritos los niveles séricos de $\mathrm{IgG}$ aportados por el calostro se mantienen en un rango normal y similar al de sus madres desde las $6 \mathrm{~h}$ hasta los 150 días de vida. Entre las 24 h y los 60 días los recién nacidos presentan un valor de IgG sérica menor en comparación a las medias de la cinética obtenida. El tamaño de la camada no influye en la concentración de $\operatorname{IgG}$ de los cabritos.

Agradecimientos. A la Dra. Vanina Marini y al Téc. Quím. Alfredo Mier, considerados como coautores de este trabajo. Al Dr. Arnaldo Mangeau por el análisis estadístico y a los alumnos del Grupo Caprino y de la Cátedra de Clínica de Grandes Animales por su colaboración en la recolección de muestras.

\section{REFERENCIAS}

1. Argentina. Ministerio de Agricultura, Ganadería y Pesca. 2011. Caracterización del sector caprino en la Argentina. On line: http://www.alimentosargentinos.gob.ar /contenido/procal/seccionprocal/caracterizacion_del_sector_caprino_en_argentina.php [Consultado: 5 de marzo de 2014].

2. Argüello A, Castro N, Capote J, Tylerc JW, Hollowayc NH. 2004. Effect of colostrum administration practices on serum IgG in goat kids. Livestock Prod Sci 90: 235-239.

3. Argüello A, Castro N, Zamorano MJ, Castroalonso A, Capote J. 2004. Passive transfer of immunity in kid goats fed refrigerated and frozen goat colostrum and commercial sheep colostrum. Small Rum Res 54: 237-241.

4. Castro N, Capote J, Morales A, Rodríguez C, Argüello A. 2009. Effects of newborn characteristics and length of colostrum feeding period on passive immune transfer in goat kids. J Dairy Sci 92: 1616-1619.

5. Chen JC, Chang CJ, The HC, Chen SY. 1999. Serum protein levels and neonatal growth rate of Nubian goat kids in Taiwan area. Small Rum Res 32: 153-160.
6. Fernández A, Ramos JJ, Lostea A, Ferrera LM, Figueras L, Verdea MT, Marca MC. 2006. Influence of colostrum treated by heat on immunity function in goat kids. Comp Immunol Microbiol Infect Dis 29: 353-364.

7. Iepema G, Eekeren N, Wagenaar JP. 2008. Effect of colostrum type on serum gamma globulin concentration, growth and health of goat kids until three months. Anales $16^{\text {th }}$ IFOAN Organic World Congress, Modena, Italy. On line: http://orgprint s.org/11943/. [Consultado: $10 \mathrm{de}$ febrero de 2014].

8. Lavoie JP, Spensley MS, Smith BP, Mihalyi J. 1989. Colostral volume and immunoglobulin $\mathrm{G}$ and $\mathrm{M}$ determinations in mares. Am J Vet Res 50: 466-470.

9. Lima A. 2008. Estudo da flutuação sérica de anticorpos maternos nos períodos pré e pós parto e transferência de imunidade passive em cabritos recém nascidos utilizando colostro bovino e caprino. Teses, Universidade de São Paulo. On line: http:// www.teses.usp.br/teses/disponiveis/11/11139/tde-15072008-124634/pt-br.php.

10. Mancini G, Vaerman C, Carbonara AO, Heremans JF. 1964. A single radial method for the immunological quantitation of proteins. Proceedings XI Colloqium on protides of biological fluid, Amsterdam, p. 370.

11. Mórtola E, Pennimpede EF, Gómez CM, Stanchi NO. 2004. Transferencia pasiva de la inmunidad materna en los animales domésticos. En: Introducción a la Inmunobiología (Ed. Univ.Nac.La Plata), La Plata, Argentina, Cap. 16.

12. Ramos JJ, Loste A, Ferrer LM, Fernández A, Castro N, Ortín A, Verde MT, Arguello A, Figueras L. 2010. Effect of addition of soybean trypsin inhibitor to colostrum on immunological status in goat kids. J Anim Physiol Anim Nutr 94: 93-98.

13. Ratht T, Kuott TT, Baker K, Qiaosw S, Kovayashi K, Yoshida M, Roopenian D, Fiebiger E, Lencer W, Blumberg RS. 2013. The immunologic functions of the neonatal Fc receptor for IgG. J Clin Immunol 33: S9-S17.

14. Rodríguez C, Castro N, Capote J, Morales A, Moreno I, Sánchez D, Argüello A. 2009. Effect of colostrum immunoglobulin concentration on immunity in Majorera goat kids. J Dairy Sci 92: 1696-1701.

15. Rudovsky A, Locher L, Zeyner A, Sobiraj A, Witter T. 2008. Measurement of immunoglobulin concentration in goat colostrum. Small Rum Res 74: 265-269.

16. Sucin M. 2003. La cría de cabras. Vet Arg 20: 109-116.

17. Tizard IR. 2009. Inmunología Veterinaria, $8^{\circ}$ ed., Elsevier, Barcelona, p. 223-238. 